\title{
Loco-regional therapy for isolated locoregional lymph node recurrence of breast cancer: focusing on surgical treatment with combined therapy
}

\author{
Kaori Terata $^{1,2}$, Ayuko Yamaguchi ${ }^{1,2}$, Ayano Ibonai ${ }^{1,2}$, Kazuhiro Imai ${ }^{2}$, Akiyuki Wakita ${ }^{2}$, Yusuke Sato ${ }^{2}$, \\ Satoru Motoyama ${ }^{2}$, Yoshihiro Minamiya ${ }^{2}$ \\ ${ }^{1}$ Department of Breast and Endocrine Surgery, Akita University Hospital, Akita, Japan; ${ }^{2}$ Department of Thoracic Surgery, Akita University Graduate \\ School of Medicine, Akita, Japan \\ Contributions: (I) Conception and design: K Terata; (II) Administrative support: Y Minamiya; (III) Provision of study materials or patients: A \\ Yamaguchi, A Ibonai, K Terata; (IV) Collection and assembly of data: A Yamaguchi, A Ibonai, K Terata; (V) Data analysis and interpretation: A \\ Yamaguchi, A Ibonai, K Terata; (VI) Manuscript writing: All authors. (VII) Final approval of manuscript: All authors. \\ Correspondence to: Kaori Terata, MD, PhD. Department of Breast and Endocrine Surgery, Akita University Hospital, 1-1-1 Hondo, Akita, 010-8543, \\ Japan. Email: trt0605@yahoo.co.jp.
}

\begin{abstract}
Advances have been made in systemic as well as locoregional treatment of primary breast cancer. Evidence, based established therapeutic strategies, for isolated locoregional lymph node recurrence is not yet sufficient. In this series, we focused especially on isolated axillary lymph node recurrence (AR) and supraclavicular lymph node recurrence (SR) in patients receiving systemic and/or radiation therapy combined with surgery. Disease free survival (DFS) in patients with AR ranged from 20 to 36 months. From $69 \%$ to $77 \%$ of all patients underwent surgical excision. The 5 -year overall survival (OS) ranged from $39 \%$ to $46 \%$. Positive lymph node metastases of primary cancer, size of the primary tumor, and R0 resection were associated with good outcomes. Longer DFS is associated with good outcomes. Limited SR data showed DFS to range from 25-27\%. Median progression free survival (PFS) was 18 months, 5-year OS rates were 24-42\%, and 5-year OS were 29-34 months. Combination therapy was an independent factor associated with better PFS as compared to local therapy only. Salvage treatment and grade of the primary tumor significantly were associated with OS on multivariate analysis. Available data, retrospective and not randomized, showed therapy combining systemic treatments and/or radiotherapy with surgery might contribute to good local control, better PFS, and longer OS.
\end{abstract}

Keywords: Breast cancer; locoregional lymph node metastases; axillary recurrence; supraclavicular recurrence

Submitted May 06, 2020. Accepted for publication May 28, 2020.

doi: $10.21037 /$ tcr-20-1690a

View this article at: http://dx.doi.org/10.21037/tcr-20-1690a

\section{Introduction}

Locoregional treatment as well as systemic therapy for primary breast cancer have both changed. NSABP B-04 (1) showed that axillary lymph node dissection (ALND) did not significantly improve 10 -year overall survival (OS). Furthermore, OS did not differ significantly between patients who did not receive ALND and those undergoing ALND after receiving a diagnosis of axillary lymph node recurrence (AR). NSABP B-32 (2), ACOSOG Z0010 (3) and other studies have provided evidence supporting the use of sentinel lymph node (SN) biopsy in patients with clinically node negative breast cancer. Omitting ALND in node negative breast cancer resulted in significantly better quality of life due to avoidance of lymphedema. Furthermore, the Z0011 trial showed that ALND could be omitted even in selected patients with positive SN status. The 10-year postoperative locoregional recurrence rate of primary breast cancer is reportedly approximately $10 \%$ (4). 
The frequency of ipsilateral AR or ipsilateral supraclavicular lymph node recurrence (SR) was reported to be $3 \%$ or less. However, omitting ALND of SN positive patients might increase the rate of $\operatorname{AR}(5,6)$. On the other hand, SR worsens distant disease free survival (DFS) and increases the risk of death (7-9).

We do not presently have sufficient evidence based established therapeutic strategies for isolated locoregional lymph node recurrence. For AR, if possible, surgical excision should be carried out followed by radiotherapy, if the patients have not previously undergone radiotherapy. As for SR, combining systemic therapy and radiotherapy, rather than performing surgery, might be recommended (10). These strategies tend to be individually tailored, and consistent decision-making policies are needed. In this review series, we focused especially on isolated AR and SR in patients receiving systemic therapies combined with surgery.

\section{Treatment of AR}

AR rates were $0.8-1.3 \%(11,12)$ in patients who underwent surgical intervention for primary breast cancer. We reviewed 4 studies (12-15) taking surgical treatment into consideration. The first author's name, year of publication, study period, and primary breast cancer information (pathological stage of primary disease, surgical therapy and adjuvant radiotherapy) are listed Table 1 . The numbers of patients were 44 to 220 . Lee et al. reported isolated locoregional recurrence. The patient ages ranged from 48 to 61 years. The pathological primary disease stage was mentioned in two studies $(12,15)$, and stages I and II accounted for at least $75 \%$ of tumors. The types of surgery performed for primary breast cancer are also listed. From $66 \%$ to $100 \%$ of patients underwent ALND. Radiotherapy was administered to $15 \%$ to $73 \%$ of patients.

Types of treatment and clinical outcomes of patients with AR are listed in Table 2. DFS was 20 to 36 months. Surgery and either radiotherapy or systemic treatments were selected. From $69 \%$ to $77 \%$ of patients underwent surgery. The 5 -year OS rates ranged from $39 \%$ to $46 \%$. Lee et al. reported isolated locoregional recurrence, and their results are thus not included in this series. de Boer et al. reported the distant DFS rate to be $35 \%$. Negative and positive prognostic factors are also listed. de Boer et al. concluded that "positive lymph node metastases of primary cancer", "tumor size of primary cancer" and "eradication of AR (R0)" were associated with good outcomes. R0 status was confirmed in $47 \%$ of patients. The R0 group had significantly better outcomes than those with residual tumor (median OS was 4.8 vs. 1.9 years, $\mathrm{P}=0.01$ ). Lee et al. and Konkin et al. noted long DFS to be associated with good outcomes. Konkin et al. mentioned that regimens combining surgery with other therapies contributed to good outcomes. Newman et al. reported initial therapies for AR: $45.5 \%$ of patients underwent surgery; $45.5 \%$ received chemotherapy; $4.5 \%$ radiotherapy; and $4.5 \%$ hormone therapy. Subtypes of AR tumors were provided in the report by Lee $e t a l$. (hormone receptor positive/HER2 negative $34 \%$, HER2 positive/hormone receptor positive or negative $35 \%$, triple negative $14 \%$, unknown $17 \%$ ).

We do not have data from a prospective randomized control study of surgical therapy for AR. While there are selection biases for AR surgery, these data show that surgery when combined with radiotherapy and/or systemic therapy has clinical benefits.

\section{Treatment of SR}

As to primary treatment of advanced breast cancer, aggressive resection of supraclavicular lymph node metastases did not improve patient outcomes (16). In terms of SR, there are no randomized control studies examining whether outcomes of patients with SR and AR improve with versus without surgical treatment. Isolated SR is a more extensive disease than isolated AR. Isolated SR was observed in $0.8-2.6 \%$ of patients who underwent curative surgery for primary breast cancer. However, patients with isolated SR have better outcomes than those with SR and distant metastases (5,17-19). van der Sangen et al. (5) reported outcomes of isolated SR, without distant metastases, in 42 patients diagnosed with breast cancer during the period from 1984 to 1994 . Median time to diagnosis of SR was 2.5 years. In total, radiotherapy was administered to 25 patients. Radiotherapy only was administered to 4 patients, while 5 received both radiotherapy and surgery, and 16 patients underwent radiotherapy with surgery and/ or hormone therapy. Seventeen patients in total were not given radiotherapy. Eleven patients received hormone therapy only, 4 chemotherapy only, and one surgery only, while one patient was untreated. Thirty-five (38\%) patients achieved complete remission, but recurrences were observed in 12 (34\% of those with complete remission). The 5-year actuarial OS rate was 38\% (95\% CI, 23-53\%). The 5 -year DFS rate was $22 \%$ (95\% CI, $8-35 \%)$. The distant DFS was better for patients given radiotherapy than 
Table 1 Stage details and adjuvant therapy for primary tumor

\begin{tabular}{|c|c|c|c|c|c|c|c|c|}
\hline $\begin{array}{l}\text { Author, year } \\
\text { (reference) }\end{array}$ & Study period & $\mathrm{n}$ & Age (years) & \multicolumn{3}{|c|}{ Stage } & Surgery & Radiotherapy \\
\hline de Boer, 2001, (12) & 1984-1994 & 59 & 61 [39-99] & NS & NS & NS & $\begin{array}{c}\text { Mastectomy + ALND 41\%; BCS } \\
+ \text { ALND 56\% }\end{array}$ & $54 \%$ \\
\hline Newman, 2000, (13) & 1982-1992 & 44 & $48[25-74]^{*}$ & $18 \%$ & $55 \%$ & $25 \%$ & $\begin{array}{c}\text { Mastectomy 5\%; Mastectomy } \\
+ \text { ALND 66\%; BCS 4\%; BCS + } \\
\text { ALND } 25 \%\end{array}$ & NS \\
\hline Lee, 2016, (14) & 2000-2010 & 104 & $\begin{array}{l}<4028 \% ; 40-50 \\
44 \% ;>5028 \%{ }^{*}\end{array}$ & $43 \%$ & $39 \%$ & $17 \%$ & Mastectomy $41 \%$; BCS 59\% ${ }^{\star \star}$ & $73 \%$ \\
\hline Konkin, 2006, (15) & 1989-2003 & 220 & 59.5 (mean) $^{\star}$ & NS & NS & NS & ALND $81 \%$; no ALND 19\%*** & $15 \%$ \\
\hline
\end{tabular}

${ }^{*}$, primary diagnosis; ${ }^{* \star}$, axillary surgery not described; ${ }^{* \star}$, breast surgery not described. NS, not stated; BCS, breast conserving surgery; ALND, axillary lymph node dissection; DFS, disease free survival.

Table 2 Therapy types, clinical outcomes, and prognostic factors of axillary lymph node recurrence (AR)

\begin{tabular}{|c|c|c|c|c|c|}
\hline $\begin{array}{l}\text { Author, year } \\
\text { (reference) }\end{array}$ & $\begin{array}{c}\text { DFS } \\
\text { (months) }\end{array}$ & Combined therapy & $\begin{array}{l}\text { Types of systemic } \\
\text { therapy }\end{array}$ & $\begin{array}{l}5 y-O S \\
\text { (median) }\end{array}$ & Negative or positive prognostic factors \\
\hline $\begin{array}{l}\text { de Boer, } \\
\text { 2001, (12) }\end{array}$ & $31[4-128]$ & $\begin{array}{c}\text { Surgery and/or RT and/or systemic } \\
69 \% \text {; RT and/or systemic 30\% }\end{array}$ & NS & $39 \%$ & $\begin{array}{c}\text { Good: negative for lymph node metastases } \\
\text { of primary cancer, small primary tumor, R0 } \\
\text { resection of AR }\end{array}$ \\
\hline $\begin{array}{l}\text { Newman, } \\
2000,(13)\end{array}$ & $20[3-117]$ & $\begin{array}{l}\text { Surgery in combination } 75 \% \text {; } \\
\text { surgery only } 2 \% \text {; RT only } 2 \% \text {; } \\
\text { systemic only } 21 \%\end{array}$ & NS & NS & NS \\
\hline $\begin{array}{l}\text { Lee, } 2016 \text {, } \\
\text { (14) }\end{array}$ & $36[4-132]$ & NS & $\begin{array}{c}\text { CT } 30 \% ; \text { HT } 35 \% ; \\
\text { RT } 35 \%\end{array}$ & $77 \%$ ** & $\begin{array}{c}\text { Negative: age }<35 \text {, high grade of primary } \\
\text { tumor, early recurrence }(<24 \text { months), triple } \\
\text { negative subtype of primary tumor }\end{array}$ \\
\hline $\begin{array}{l}\text { Konkin, } \\
2006,(15)\end{array}$ & $26[2-143]$ & Surgery $73 \%{ }^{*}$ & $\begin{array}{c}\text { CT } 24 \% ; \text { HT } 68 \% ; \\
\text { RT } 65 \%\end{array}$ & $46 \%$ & $\begin{array}{c}\text { positive factors for OS: long DFS ( }>2.5 \text { years), } \\
\text { no RT with primary surgery, no symptoms, } \\
\text { combination of surgery with RT and/or } \\
\text { systemic therapy }\end{array}$ \\
\hline
\end{tabular}

*, combination therapy not described; **, all data pertaining to isolated locoregional recurrence. NS, not stated; DFS, disease free survival; $\mathrm{RT}$, radiotherapy; $\mathrm{CT}$, chemotherapy; $\mathrm{HT}$, hormone therapy; $\mathrm{R} 0$, microscopic complete resection.

for those not receiving radiotherapy $(\mathrm{P}=0.06)$. However, only a few retrospective studies with small sample sizes have examined this issue $(19,20)$. Reddy et al. (17) reviewed longterm outcomes of patients with SR after initial treatment with doxorubicin-based chemotherapy and mastectomy. Although the patients with locoregional recurrence including SR and lymphatic invasion or vascular invasion of primary tumors have poorer distant DFS (hazard ratio, 1.96, $\mathrm{P}=0.004)$, OS of patients with isolated SR did not different significantly from that of those with more extensive locoregional disease.

There are a few reports describing the utility of surgical treatment for isolated SR $(18,21)$. However, there have been no randomized controlled trials comparing surgical to non-surgical treatment for SR. Chen et al. identified 63 patients with SR without distant metastases in a single institute. Median follow-up was 58.3 months. Thirtyfive $(56 \%)$ of the 63 patients died within the observation period. Median DFS was 25 months. The only significant risk factor was age at diagnosis of SR (>40). The 5 -year OS rate was significantly better for patients in the operation group (42.4\% vs. $16.3 \%)$. The patients with isolated SR had 5-year OS nearly equivalent to that of patients who had isolated local recurrence (33.6\% vs. $34.9 \%$ ), but better than 
that of patients with distant metastases (33.6\% vs. 9.1\%). Of course, there might be a selection bias, not only in terms of systemic therapy or radiotherapy, but also surgery for SR which is effective for neck control and improving the survival rate. Pederson et al. investigated early breast cancer patients with isolated ipsilateral SR. They extracted 305 patients diagnosed with SR, but free of distant metastases, from the database of the Danish Breast Cancer Cooperative Group. As to the primary tumor, $74 \%$ of patients had axillary lymph node metastases. Forty-six percent of patients were hormone receptor positive. DFS was 27 months (range, $2-114$ months). The tumor sizes of SR cases were $\leq 10 \mathrm{~mm}$ in $30 \%, 11-20 \mathrm{~mm}$ in $34 \%$, and $>20 \mathrm{~mm}$ in $19 \%$. Nearly half of the patients had developed SR by 2 years after the primary surgery. The types of therapy for SR were surgery and radiotherapy in 10\% (excisional surgery: 19\%, curative radiotherapy: $33 \%$ ), endocrine and chemotherapy in $11 \%$ (endocrine therapy: 40\%, chemotherapy: 45\%), local and systemic therapy in 26\% (systemic therapy only: $49 \%$, no systemic therapy: $25 \%$ ). The 5 -year progression free survival (PFS) rate was $15 \%$, median PFS was 18 months, 5 -year OS was 24\%, and median OS was 29 months. As to prognostic factors, complete remission was related to better outcomes $(\mathrm{P}<0.0001)$, and systemic therapy prolonged PFS. Most notably, a combination of systemic and loco-regional treatment reduced progression. All of these factors were identified by univariate analysis. On multivariate analysis, combination therapy was an independent factor associated with improved PFS, as compared to local therapy only, and negative lymph node status and low tumor grade at the diagnosis of the primary disease were also independent factors related to PFS. Salvage treatment and tumor grade were significantly associated with OS.

In summary, we have reviewed a small number of retrospective and non-randomized studies. The outcomes of patients with isolated SR are better than those of patients with distant metastases. The effectiveness of surgical resection for improving the OS of patients with isolated SR remains controversial, while regimens combining systemic treatments and radiotherapy with surgery might contribute to good neck control, better PFS, and longer OS. The treatment decisions must be made by cancer board, and the risks of surgical treatment must be taken into consideration. The results of further investigations are thus needed.

\section{Future perspectives}

There is a report describing recurrence risk according to receptor phenotypes (22). Lowery et al. investigated the relationship between locoregional recurrence and the primary cancer subtype. Estrogen receptor and/or progesterone receptor positive patients had a lower risk of locoregional recurrence than those with triple negative and HER2/neu-over-expressing tumors after breast conserving surgery (RR 0.38; 95\% CI: 0.23-0.61, RR 0.34; 95\% CI: $0.26-0.45$, respectively) Mastectomy patients had results very similar to those of patients receiving breast conserving surgery. HER2/neu-over-expressing tumors carried a higher risk of locoregional recurrence than triple negative tumors after breast conserving surgery (RR 1.44; 95\% CI: 1.061.95). However, after mastectomy, these two groups showed no difference in locoregional recurrence rates. HER2/ neu-over-expressing and triple negative tumors tended to have a high risk of locoregional recurrence, regardless of whether breast conserving surgery or mastectomy had been performed, suggesting that local and systemic treatments should be tailored to each subtype. Michel et al. (23) also reported risk prediction based on locoregional recurrence by using the CPS + EG score which predicts distant metastases. The score is calculated based on clinical stage, post-treatment pathological stage, estrogen receptor status, and tumor grade. They divided patients into 6 prognostic groups with 5-year locoregional recurrence free survival and 5 -year distant metastasis free survival, which ranged from $100-41 \%(\mathrm{P}=0.02)$, and $96-35 \%(\mathrm{P}<0.0001$, respectively). If risks of locoregional recurrence can be reliably assessed, tailored adjuvant treatment for primary breast cancer might this type of recurrence and thereby improve the outcomes of patients with isolated AR, SR, and other forms of locoregional recurrence.

Surgical treatment for locoregional recurrence aims not only to cure but also diagnose metastatic lymph nodes. Thangarajah et al. (24) reported discordance of receptor status between primary and metastatic sites of SR. Discordance rates between primary tumor and metastatic sites in terms of estrogen, progesterone, and Her2 receptor status were $20.0 \%, 36.8 \%$, and $29.4 \%$, respectively. When treating SR, combination therapy achieves better local control, longer DFS, improved rates of being distant metastases free and better OS, such that optimal selection of systemic therapy is crucial. Surgical treatment of SR is also contributes to improved outcomes.

In terms of systemic therapy, we now have a wider range of novel drugs for breast cancer. Molecularlytargeted therapies such as anti- HER2 agents, including trastuzumab, pertuzumab and T-DM1 $(25,26)$, immune 
checkpoint inhibitors (ICI) such as humanized monoclonal anti-PD-L1 antibody (Atezolizumab) (27), and PARP inhibitors have shown efficacy for BRCA (BReast CAncer gene)-positive HER2 negative metastatic breast cancers (28) and are thereby contributing to better outcomes not only for metastatic breast cancer patients but also those receiving adjuvant therapy for primary breast cancer. Regimens combining local treatment and systemic therapy appear to be highly effective, even potentially curative, and further investigations are thus needed.

\section{Conclusions}

We reviewed clinical outcomes of combining surgery with other treatments for AR, and examined the role of surgery for isolated SR. Although further investigation employing a prospective randomized clinical study design is needed, appropriate surgical therapy with minimum morbidity combined with radiotherapy and/or the newer, effective systemic agents improves the clinical outcomes of breast cancer patients with locoregional lymph node metastases.

\section{Acknowledgments}

Funding: None.

\section{Footnote}

Provenance and Peer Review: This article was commissioned by the Guest Editors (Tadahiko Shien and Kaori Terata) for the series "Loco-regional therapy for metastatic breast cancer" published in Translational Cancer Research. The article was sent for external peer review organized by the Guest Editors and the editorial office.

Conflicts of Interest: All authors have completed the ICMJE uniform disclosure form (available at http://dx.doi. org/10.21037/tcr-20-1690a). The series "Loco-regional therapy for metastatic breast cancer" was commissioned by the editorial office without any funding or sponsorship. KT served as the unpaid Guest Editor of the series. The authors have no other conflicts of interest to declare.

Ethical Statement: The authors are accountable for all aspects of the work in ensuring that questions related to the accuracy or integrity of any part of the work are appropriately investigated and resolved.
Open Access Statement: This is an Open Access article distributed in accordance with the Creative Commons Attribution-NonCommercial-NoDerivs 4.0 International License (CC BY-NC-ND 4.0), which permits the noncommercial replication and distribution of the article with the strict proviso that no changes or edits are made and the original work is properly cited (including links to both the formal publication through the relevant DOI and the license). See: https://creativecommons.org/licenses/by-nc-nd/4.0/.

\section{References}

1. Fisher B, Redmond C, Fisher ER, et al. Ten-year results of randomized clinical trial comparing radical mastectomy and total mastectomy with or without radiation. $\mathrm{N}$ Engl J Med 1985;312:674-81.

2. Krag DN, Anderson SJ, Julian TB, et al. Sentinel-lymphnode resection compared with conventional axillarylymph-node dissection in clinically node-negative patients with breast cancer: overall survival findings from the NSABP B-32 randomized phase 3 trial. Lancet Oncol 2010;11:927-33.

3. Hunt KK, Ballman KV, McCall LM, et al. Factors associated with local-regional recurrence after a negative sentinel node dissection: results of the ACOSOG Z0010 trial. Ann Surg 2012;256:428-36.

4. van Tienhoven G, Voogd AC, Peterse JL, et al. Prognosis after treatment for loco-regional recurrence after mastectomy or breast conserving therapy in two randomised trials(EORTC 10801 and DBCG-82TM). EORTC Breast Cancer Cooperative Group and the Danish Breast Cancer Cooperative Group. Eur J Cancer 1999;35:32-8.

5. van der Sangen MJ, Coebergh JW, Roumen RM, et al. Detection, treatment, and outcome of isolated supraclavicular recurrence in 42 patients with invasive breast carcinoma. Cancer 2003;98:11-7.

6. Naik AM, Fey J, Gemignani M, et al. The risk of axillary relapse after sentinel lymph node biopsy for breast cancer is comparable with that of axillary lymph node dissection: a follow-up study of 4008 procedures. Ann Surg 2004;240:462-68; discussion 468-71.

7. Anderson SJ, Wapnir I, Dignam JJ, et al. Prognosis after ipsilateral breast tumor recurrence and locoregional recurrences in patients treated by breast-conserving therapy in five National Surgical Adjuvant Breast and Bowel Project protocols of node-negative breast cancer. J Clin Oncol 2009;27:2466-73. 
8. Montagna E, Bagnardi V, Rotmensz N, et al. Breast cancer subtypes and outcome after local and regional relapse. Ann Oncol 2012;23:324-31.

9. Wapnir IL, Anderson SJ, Mamounas EP, et al. Prognosis after ipsilateral breast tumor recurrence and locoregional recurrences in five National Surgical Adjuvant Breast and Bowel Project node-positive adjuvant breast cancer trials. J Clin Oncol 2006;24:2028-37.

10. Pergolizzi S, Adamo V, Russi E, et al. Prospective multicenter study of combined treatment with chemotherapy and radiotherapy in breast cancer women with the rare clinical scenario of ipsilateral supraclavicular node recurrence without distant metastases. Int J Radiat Oncol Biol Phys 2006;65:25-32.

11. Shen SC, Liao CH, Lo YF, et al. Favorable outcome of secondary axillary dissection in breast cancer patients with axillary nodal relapse. Ann Surg Oncol 2012;19:1122-8.

12. de Boer R, Hillen HF, Roumen RM, et al. Detection, treatment and outcome of axillary recurrence after axillary clearance for invasive breast cancer. Br J Surg 2001;88:118-22.

13. Newman LA, Hunt KK, Buchholz T, et al. Presentation, management and outcome of axillary recurrence from breast cancer. Am J Surg 2000;180:252-6.

14. Lee MY, Chang WJ, Kim HS, et al. Clinicopathological Features and Prognostic Factors Affecting Survival Outcomes in Isolated Locoregional Recurrence of Breast Cancer: Single-Institutional Series. PLoS One 2016;11:e0163254.

15. Konkin DE, Tyldesley S, Kennecke H, et al. Management and outcomes of isolated axillary node recurrence in breast cancer. Arch Surg 2006;141:867-72.

16. Kim K, Kim SS, Shin KH, et al. Aggressive Surgical Excision of Supraclavicular Lymph Node Did Not Improve the Outcomes of Breast Cancer With Supraclavicular Lymph Node Involvement (KROG 16-14). Clin Breast Cancer 2020;20:51-60.

17. Reddy JP, Levy L, Oh JL, et al. Long-term outcomes in patients with isolated supraclavicular nodal recurrence after mastectomy and doxorubicin-based chemotherapy for breast cancer. Int J Radiat Oncol Biol Phys 2011;80:1453-7.

18. Chen SC, Chang HK, Lin YC, et al. Prognosis of breast cancer after supraclavicular lymph node metastasis: not a distant metastasis. Ann Surg Oncol 2006;13:1457-65.

19. Deo SV, Purkayastha J, Shukla NK, et al. Intent of therapy in metastatic breast cancer with isolated ipsilateral supraclavicular lymph node spread-a therapeutic dilemma.
J Assoc Physicians India 2003;51:272-5.

20. Pergolizzi S, Settineri N, Russi EG, et al. Supraclavicular lymph node metastases (SLM) from breast cancer as only site of distant disease:has radiotherapy any role? Anticancer Res 1997;17:2303-8.

21. Pedersen AN, Møller S, Steffensen KD, et al. Supraclavicular recurrence after early breast cancer: a curable condition? Breast Cancer Res Treat 2011;125:815-22.

22. Lowery AJ, Kell MR, Glynn RW, et al. Locoregional recurrence after breast cancer surgery: a systematic review by receptor phenotype. Breast Cancer Res Treat 2012;133:831-41.

23. Michel LL, Sommer L, González Silos R, et al. Locoregional risk assessment after neoadjuvant chemotherapy in patients with primary breast cancer: clinical utility of the CPS + EG score. Breast Cancer Res Treat 2019;177:437-46.

24. Thangarajah F, Vogel C, Pahmeyer C, et al. Profile and outcome of supraclavicular metastases in patients with metastatic breast cancer: discordance of receptor status between primary and metastatic site. Anticancer Res 2018;38:6023-6.

25. Baselga J, Cortés J, Kim SB, et al;CLEOPATRA Study Group. Pertuzumab plus trastuzumab plus docetaxel for metastatic breast cancer. N Engl J Med 2012;366:109-19.

26. Verma S, Miles D, Gianni L, et al. Trastuzumab emtansine for HER2-positive advanced breast cancer. N Engl J Med 2012;367:1783-91.

27. Schmid P, Adams S, Rugo HS, et al. Atezolizumab and Nab-Paclitaxel in Advanced Triple-Negative Breast Cancer. N Engl J Med 2018;379:2108-21.

28. Robson ME, Tung N, Conte $\mathrm{P}$, et al. OlympiAD final overall survival and tolerability results: Olaparib versus chemotherapy treatment of physician's choice in patients with a germline BRCA mutation and HER2-negative metastatic breast cancer. Ann Oncol 2019;30:558-66.

Cite this article as: Terata K, Yamaguchi A, Ibonai A, Imai K, Wakita A, Sato Y, Motoyama S, Minamiya Y. Loco-regional therapy for isolated locoregional lymph node recurrence of breast cancer: focusing on surgical treatment with combined therapy. Transl Cancer Res 2020;9(8):5038-5043. doi: 10.21037/tcr20-1690a 